\title{
TRIBOLOGICAL CHARACTERIZATION OF PARTICULATE MMC DEVELOPED BY STIR CASTING PROCESS
}

\author{
Raghavendra $\mathrm{N}^{1}$ and V S Ramamurthy ${ }^{2}$ \\ ${ }^{1}$ Research Scholar, Mechanical Engineering Department, B N M Institute of Technology, \\ Bangalore \\ ${ }^{2}$ Professor and Head, Mechanical Engineering Department, Yellamma Dasappa Institute \\ of Technology, Bangalore
}

\begin{abstract}
The present work aims at the development of particulate metal matrix composite using Aluminum alloy (AL 7075) as the matrix material and alumina $\left(\mathrm{Al}_{2} \mathrm{O}_{3}\right)$, Silicon Carbide $(\mathrm{SiC})$ and Hybrid $\left(\mathrm{Al}_{2} \mathrm{O}_{3}+\mathrm{SiC}\right)$ as Reinforcement. $\mathrm{Al}_{2} \mathrm{O}_{3}$ is reinforced in the weight fraction of $3 \%, 6 \%, 9 \%$ and $12 \%$ with the particle size varying between 50 microns to 150 microns. SiC in the weight fraction of 3\%, 6\%, 9\% and 12\% \& $\mathrm{Al}_{2} \mathrm{O}_{3}+\mathrm{SiC}$ in the weight fraction of $3 \%+3 \%, 6 \%+3 \%, 9 \%+3 \%$ and $12 \%+3 \%$. The aluminum alloy was melted at $700^{\circ} \mathrm{C}$ in an electrical heating furnace for 20 minutes and the reinforcement is heated separately at $350^{\circ} \mathrm{C}$ was added in the form of powder. The molten metal was stirred for 5 minutes at the temperature of $700^{\circ} \mathrm{C}$, followed by pouring in to the metal mold. Optical micro graph of the developed composite was obtained to demonstrate the distribution of the reinforcement in the matrix. The hardness tests was carried out to determine the effect of reinforcement on the hardness of the composites. The hardness of the composite was found increases with the increase in reinforcement weight fraction. The wear test carried out at various speed, load and sliding distance which indicates improvement in the mechanical properties of the composites. The wear resistance of the composite reduces with the increase in the Reinforcement weight fraction. The wear resistance reduces with the increase in speed, Also wear rate increases with the increase in applied load. As the sliding distance increases the wear of the MMC increases for all specimens. The coefficient of friction was reduces at higher weight fraction as compared to lower weight fraction of reinforcements.. The noise during running the test was reduced in case of Hybrid composite as compared to composite with either alumina or silicon carbide as reinforcement. The investigation carried out will lead to development of the composite system with high strength, improved wear resistant, light weight for automobile parts like disc brake, piston, cylinder liner, drive shaft etc.
\end{abstract}

\section{KEY WORDS}

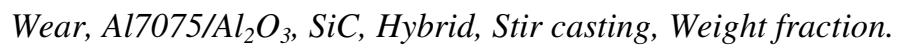

DOI: $10.14810 /$ ijmech.2016.5403 
International Journal of Recent Advances in Mechanical Engineering (IJMECH) Vol.5, No.4, November 2016

\section{INTRODUCTION}

The innovation in the materials domain opened unlimited possibility for the modern automobile and aircraft industries to develop light weight \& high strength parts. The main objective of developing composite with new material system is to obtain high strength, light weight, high wear resistance\& fuel efficient, pollution free, recyclable properties. The Metal Matrix composite is a unique material system which try to address all the requirement of the modern material behavior. The process of developing and commercializing needs the research data obtained on all possible combinations, the idea which has to be developed, \& validated followed by pilot development and prototype development, finally application or development for commercial use[1].

The reinforcing material selected as ceramic material as they are light weight and have the capacity to withstand high temperature and wear. The combined density of reinforcement and matrix in a composite material is very less as compared to conventional materials like steel and cast iron. The reinforcement are of oxides, carbides, borides. The oxides are more stable at high temperature with the aluminum alloy hence more widely used ceramics are oxides. The reinforcement shape chosen will have effect on the properties and cost of production. Most of the investigations were carried on silicon carbide and aluminum oxide from the beginning. The silicon carbide $(\mathrm{SiC})$ is costlier compared to alumina $\left(\mathrm{Al}_{2} \mathrm{O}_{3}\right)$, also presence of carbon in $\mathrm{SiC}$ will give rise to interface reactions in aluminum matrix. Careful control of the melting temperature and mixing time is essential for composite development with $\mathrm{SiC}$. In $\mathrm{Al} / \mathrm{Al}_{2} \mathrm{O}_{3}$ reinforced composite the reinforcement is more stable at high temperature and improved properties are obtained. $40 \%$ of the final product cost depends on the material cost and $30 \%$ of the cost depends on the manufacturing process.

The ceramic material will not have the ability to exhibit the behavior as used alone instead of incorporation in the Matric. The use of reinforcements with oxides or borides or carbides of metals can effectively enhance the property. The graphite or $\mathrm{MSO}_{2}$ found to influence the lubricating effect of the composite. The ceramics are hard materials with melting point at above $1500^{\circ} \mathrm{C}$. The hard ceramics increases in the matrix increases the wear resistance and with good bond between the matrix and reinforcements enhances the strength and soft nature of ceramics increases the lubrication effect, reduces the effect of noise and vibration during running. The SiC ceramic reduces the noise and reduces the thermal expansion coefficient. It also conducts heat three times more effectively. These requirements of ceramics are used in developing the hybrid metal matrix composites.

The stir casting process is one of the liquid state process which is most economical for mass production for structural applications. The process is carried out by melting the matrix in a furnace, a vortex is created by continuously stirring the melt and addition of the reinforcement in the particulate form by direct pouring or through pressured gas. Care must be taken to avoid entrapment of the gas to avoid porosity. The degree of strengthening depends on amount of particulate volume fraction distribution, shape \& size of particles etc. Alumina has received attention as reinforcing material due to its low cost, availability, high strength and hardness. Researchers studied SIC, $\mathrm{AL}_{2} \mathrm{O}_{3}, \mathrm{~B}_{4} \mathrm{C}$, clay, graphite as reinforcement in developing MMC. The volume fraction of the particulates are less than $30 \%$ for structural application and as high as $70 \%$ 
for the packaging industries. The strength of the composite is found to influence by matrix material there-fore the widely used low density aluminum alloy such as use $2 \mathrm{xxx}, 6 \mathrm{xxx}$ and $7 \mathrm{xxx}$ series found increased use for enhanced property.

The effect of reinforcement quantity on the composite is significant. The volume fraction or weight fraction of reinforcement alters the mechanical properties of the composite materials. The strength and wear resistance of the composite can be improved significantly by addition of the various percentages of reinforcements as compared to unreinforced alloy. Most of the research has been carried out to study the strength of the composite with respect to weight fraction but the inherent property of the $\mathrm{Al}_{2} \mathrm{O}_{3}$ makes it necessary to investigate the wear and friction behavior. The parts like disc brake, piston, cylinder liner which experiences higher wear can be fabricated by composite based on the wear behavior at high speed, load and temperature conditions. The effect of $\mathrm{Al}_{2} \mathrm{O}_{3}$ particles weight fraction and size on the properties of the composite was studied [6].addition of $\mathrm{Al}_{2} \mathrm{O}_{3}$ particulate to $\mathrm{A} 365$ - aluminum alloy increases dry wear [13] Addition of $\mathrm{Mg}$ and $\mathrm{Zr}$ up to $1 \%$ in aluminum will increase the strength and toughness by wetting the reinforcement.

\section{EXPERIMENT}

In the present study Alumina is incorporated in to the Aluminum matrix by melting and stirring the mixture. The reinforcement is added to the matrix which is in the liquid state. The fig 1 shows the stir casting process in which the stirrer is used to disperse the reinforcement particle to get homogeneity by inducing vortex.

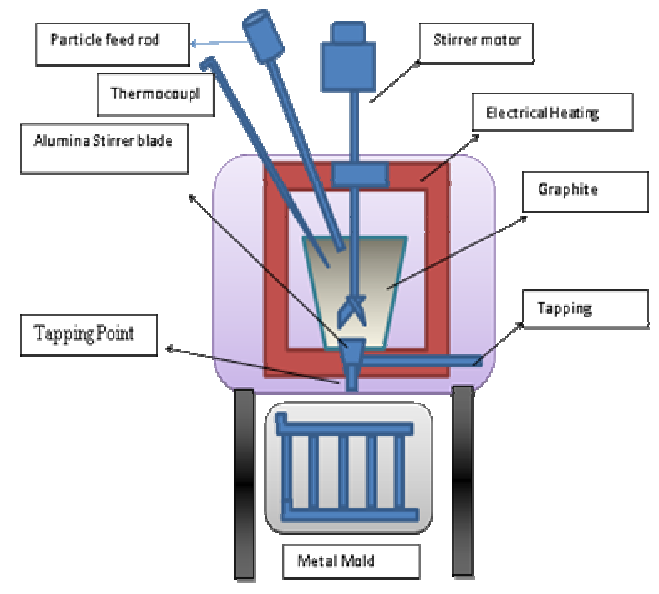

Figure 1. Stir casting process set up.

The aluminum alloy used for the present study was Al7075 supplied by Hindalco Ltd, which contains $\mathrm{Zn}$ as major alloying element $(6.1 \%)$.The matrix material has good response to heat treatment and age hardening. It is light weight and withstands high temperature compared to other series of alloy. The composition and properties of the Al7075 is shown in table 1. 
International Journal of Recent Advances in Mechanical Engineering (IJMECH) Vol.5, No.4, November 2016

Table 1. Properties of Matrix

\begin{tabular}{|l|l|}
\hline Mechanical properties & \\
\hline Brinell Hardness & $150 \mathrm{BHN}$ \\
\hline Ultimate tensile strength & $572 \mathrm{MPa}$ \\
\hline Tensile yield strength & $503 \mathrm{MPa}$ \\
\hline Modulus of Elasticity & $71.7 \mathrm{GPa}$ \\
\hline Poisson's ratio & 0.33 \\
\hline Fatigue strength & $159 \mathrm{MPa}$ \\
\hline Machinability & $72 \%$ \\
\hline Shear modulus & $26.9 \mathrm{GPa}$ \\
\hline Shear strength & $330 \mathrm{Mpa}$ \\
\hline
\end{tabular}

Table 2. Properties of Reinforcements

\begin{tabular}{|l|l|l|}
\hline Property & $\mathbf{A l}_{\mathbf{2}} \mathbf{O}_{\mathbf{3}}$ & $\mathbf{S i C}$ \\
\hline Melting Point ${ }^{\circ} \mathrm{C}$ & 2072 & 2200 \\
\hline Hardness Mohr's scale & 1175 & 2800 \\
\hline Density $(\mathrm{g} / \mathrm{cm} 3)$ & 3.69 & 3.1 \\
\hline $\begin{array}{l}\text { Coefficient of thermal } \\
\text { expansion }\left(\mathrm{micron} / \mathrm{m}^{\circ} \mathrm{C}\right)\end{array}$ & 8.1 & 4.0 \\
\hline Fracture Toughness & 3.5 & 4.6 \\
\hline Poisson's ratio & 0.21 & 0.14 \\
\hline
\end{tabular}

The Ceramic material used in the work is Alumina $\left(\mathrm{Al}_{2} \mathrm{O}_{3}\right)$ \& Silicon Carbide $(\mathrm{SiC})$ supplied by Prefene ceramics, Bangalore, in the form of powder of particle size 50 to 200 microns. The properties of alumina 7 Silicon Carbide is shown in table 2. The weight fractions of the particulates are $3 \%, 6 \%, 9 \%$ and $12 \%$. For one kg melt the reinforcement material for $3 \%$ weight fraction was $30 \mathrm{gms}$ and matrix material was $970 \mathrm{gms}$. Similarly for the weight fraction of $6 \%, 9 \%$ ,12\% the reinforcement of $60 \mathrm{gms}, 90 \mathrm{gms}, 120 \mathrm{gms}$ were used. 
The matrix material was in the form of bar of $20 \mathrm{mmX} 20 \mathrm{~mm} \mathrm{c} / \mathrm{s}$ and $100 \mathrm{~mm}$ length which are cleaned, placed inside the graphite crucible and melted in electric furnace. The melting temperature was kept at $700^{\circ} \mathrm{C}$ so as to get the desired viscosity of the melt. The reinforcement particles were heated to $350^{\circ} \mathrm{C}$ separately and added to the melt, the stirring of the mixture was carried by alumina rod to get uniform distribution of particles. The melt was treated with degasifier to remove the oxides and entrapped air before pouring. The stirring was carried for 10 minutes at $300 \mathrm{rpm}$ and the melt was poured in to the Metal mold. The castings was obtained in the form of rod diameter $20 \mathrm{~mm}$ and length $200 \mathrm{~mm}$. The pouring temperature was recorded as $700^{\circ} \mathrm{C}$.
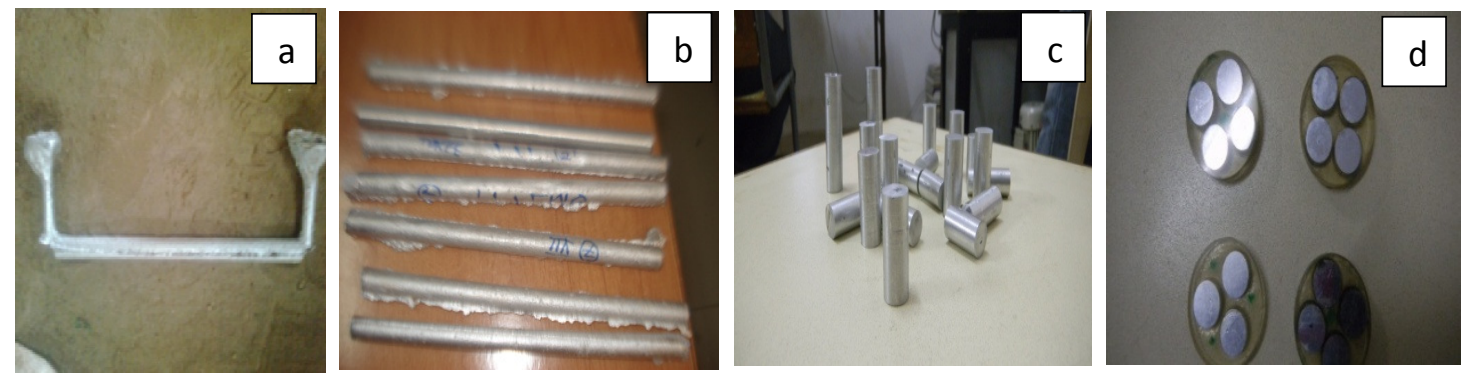

Figure 2 As cast Composite specimens and Specimens for wear test and Microstructure Analysis Cast specimen, b) Machined Specimen c) wear test specimen, d) Microstructure Specimen

The casted specimens were turned to reduce the diameter to $16 \mathrm{~mm}$ their by removing the oxide layer and rough surface from the castings. The specimen with diameter $16 \mathrm{~mm}$ and length $30 \mathrm{~mm}$ were used for hardness test and microstructure analysis. The wear test specimens were prepared with diameter $12 \mathrm{~mm}$ and length $25 \mathrm{~mm}$.

The microstructure characterization was carried out as per ASTM E407 standards in which the specimen id grinded initially followed by polishing with 300,600, 800, 1000, 1200 grit size sand paper. The samples are grounded on golden touch 1,2,3,4 grit size emery sheet. Polishing was carried out in with $\mathrm{Al} 2 \mathrm{O} 3$ paste of 1200 mesh with $250 \mathrm{rpm}$ speed of polishing disc, followed by etching by killer's solution. The optical micrograph was obtained at 50x in etched and un-etched condition for all the casted specimens, the microstructure is as shown in the fig 3 .
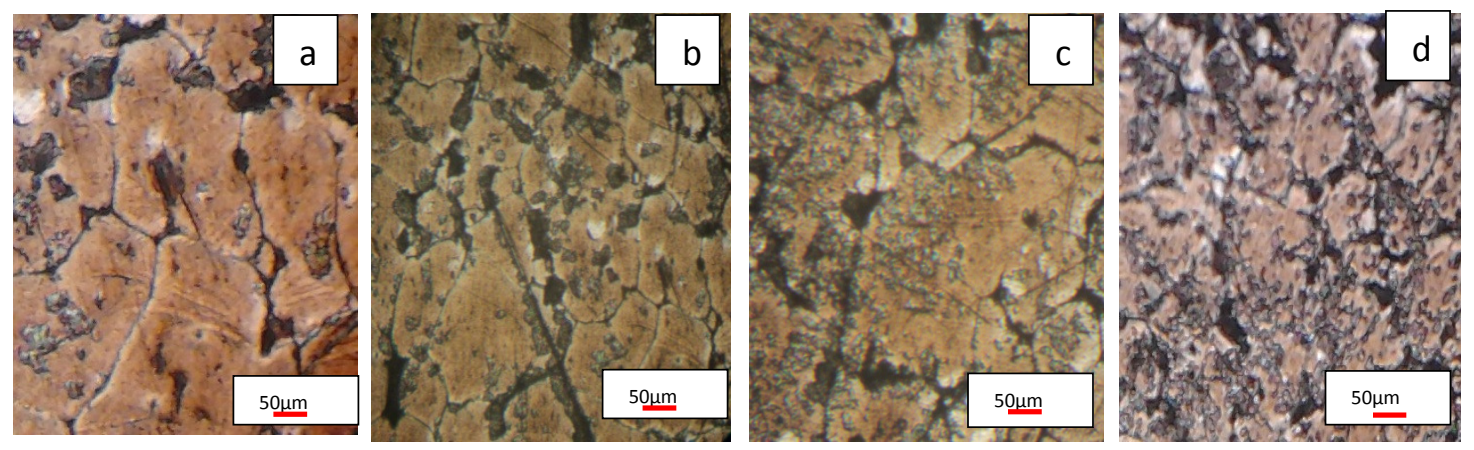

Figure 3. Optical micrograph of Alumina reinforces composite with different weight fraction. a) Al 7075 with $3 \% \mathrm{Al}_{2} \mathrm{O}_{3}$, b) $\mathrm{Al} 7075$ with6\% $\mathrm{Al}_{2} \mathrm{O}_{3}$, c) $\mathrm{Al} 7075$ with $9 \% \mathrm{Al}_{2} \mathrm{O}_{3}$, d) $\mathrm{Al} 7075$ with $12 \% \mathrm{Al}_{2} \mathrm{O}_{3}$ 

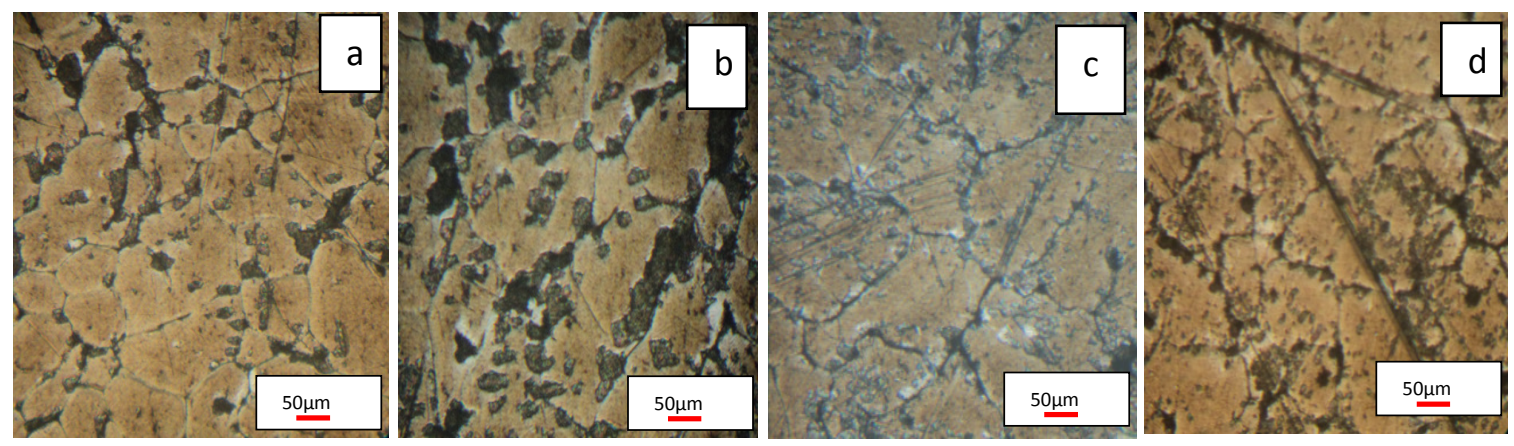

Figure 4. Optical micrograph of Silicon carbide reinforced Composite specimen different weight fraction. a) $\mathrm{Al} 7075$ with $3 \% \mathrm{SiC}$, b) Al 7075 with6\% $\mathrm{SiC}$, c) Al 7075 with $9 \% \mathrm{SiC}$, d) Al 7075 with $12 \% \mathrm{SiC}$
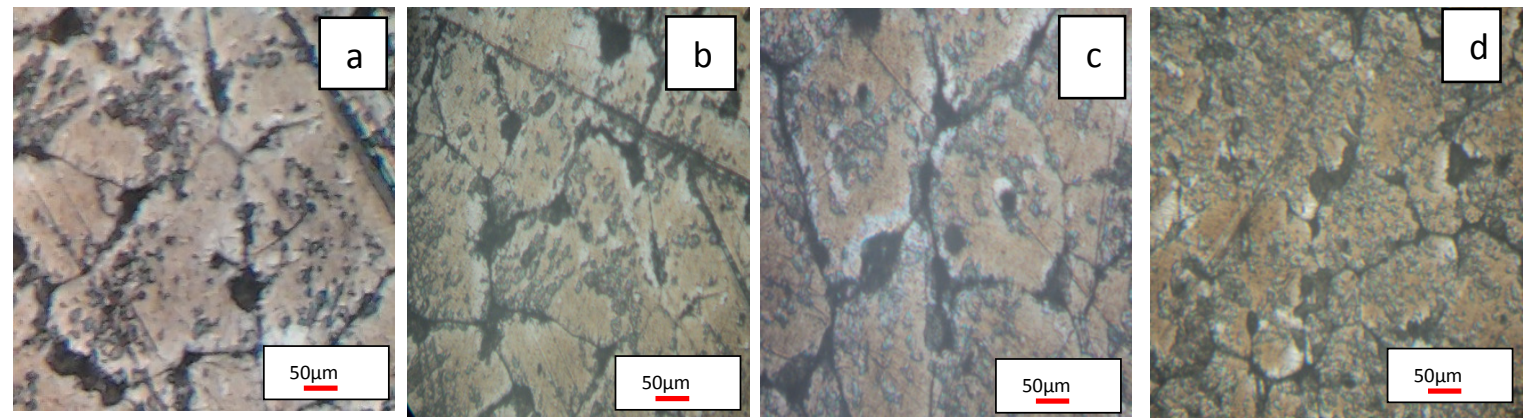

Figure 5. Optical micrograph of Hybrid composite with various weight fraction. . a) $\mathrm{Al} 7075$ with $3 \% \mathrm{Al}_{2} \mathrm{O}_{3}$ $+3 \% \mathrm{SiC}$, b) $\mathrm{Al} 7075$ with $6 \% \mathrm{Al}_{2} \mathrm{O}_{3}+3 \% \mathrm{SiC}$, c) $\mathrm{Al} 7075$ with $9 \% \mathrm{Al}_{2} \mathrm{O}_{3}+3 \% \mathrm{SiC}$, d) $\mathrm{Al} 7075$ with $12 \%$ $\mathrm{Al}_{2} \mathrm{O}_{3}+3 \% \mathrm{SiC}$

The hardness test conducted with the Brinell and Vickers harness tester. The hardness measured was bulk hardness as well as micro hardness which is an average estimation of hardness. The load of $250 \mathrm{~kg}$ with $5 \mathrm{~mm}$ ball indenter was used for Brinell test and 20kg load and 10 seconds dwell was used for Vickers hardness test. The BHN, VHN for various weight fraction of reinforcement are shown in fig 6.

Pin on disc wear tester id used for the evaluation of wear behavior of the composite material. The weight loss method was followed with the weighing scale of $1 \mathrm{mg}$ accuracy. Flat faced cylindrical specimens wear made to revolve with the rotation hardened steel disc at various loads and speeds. In this work wear of pin specimen was determined by pin on disc wear tester Supplied by DUCOM, Bangalore. The disc material was En-30 steel with Rockwell hardness 60HRC and surface roughness of $1.3 \mathrm{Ra}$ is used. The wear track diameter was selected based on the mean diameter of the disc. The pin on disc wear test carried out as per ASTM G99 standards. The machine had the provision for digital display of wear volume micron and friction force in newton by electronic force sensor and LVDT. 


\section{RESULTS AND DISCUSSIONS}

The developed composite subjected to various types of mechanical test to study the behavior of the composite and correlation of the wear rate with weight fraction and type of reinforcement. The microstructure of MMC is presented for three different reinforcements. it is clear from the microstructure that the distribution of the reinforcement is achieved by stirring the melt. The degree of uniformity depends on the density difference between the molten matrix and the hard ceramics with increase in this value the settling of the ceramics takes place at the bottom. The lighter the ceramic that floats over the surface of the molten alloy.

Also the agglomeration of the reinforcements occurs due to difference in the coefficient of thermal expansion. The MMC will develop weak bond at the interface due to interfacial reactions if the holding time is too long before pouring. The type of mold material and the cooling rate decides the grain boundary size of the MMC. All the above parameters of the developed MMC can be analyzed by subjecting to optical microscopy and scanning electron microscopy.
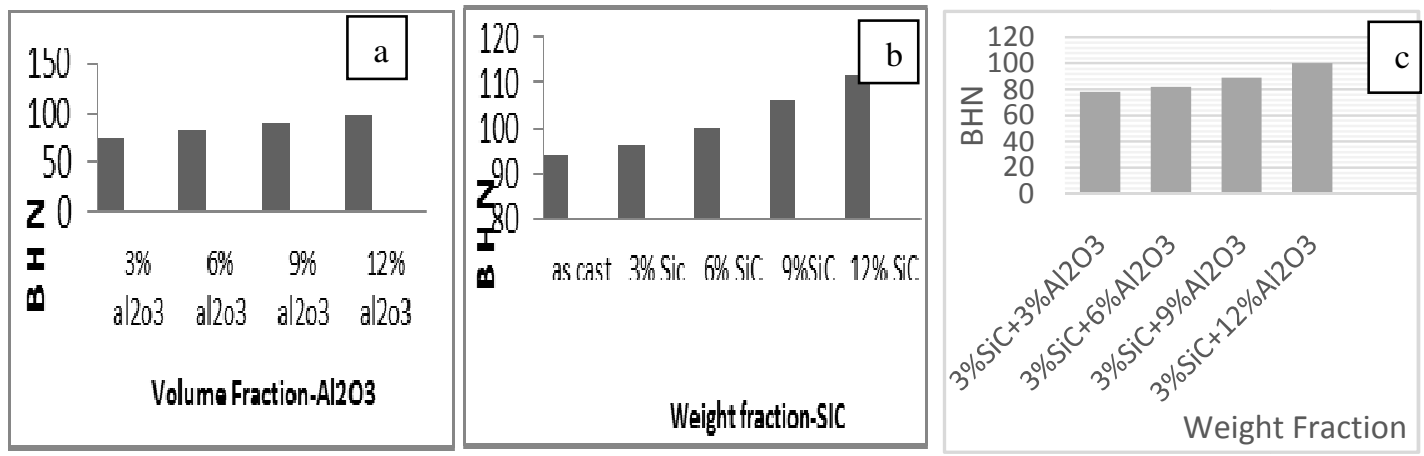

Figure 6 Brinell and Vickers Hardness values of composite with varying weight fraction a) $\mathrm{Al}_{17075}+\mathrm{Al}_{2} \mathrm{O}_{3}$ 2) $\mathrm{Al} 7075+\mathrm{SiC} 3) \mathrm{Al} 7075+\mathrm{Al}_{2} \mathrm{O}_{3}+\mathrm{SiC}$

The hardness of the composite found to increase with increase in weight fraction of the reinforcements for all the composite materials as seen from the figure 6 . The composite reinforced with the $\mathrm{SiC}$ as reinforcements exhibits maximum hardness.
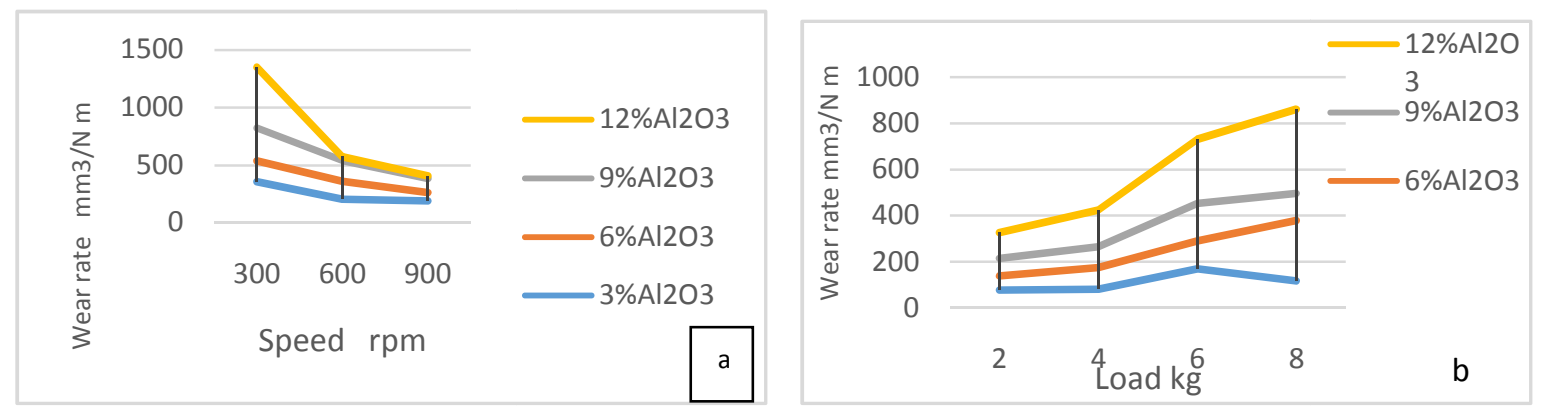

Figure 7 Wear rate vs Weight fraction for Al7075+ $\mathrm{Al}_{2} \mathrm{O}_{3}$ compositeat varying a) Speed 2) Load 
The wear rate varies with the speed as shown in fig 7 ,as the speed increases the wear rate reduces ,this is due to the increase in delamination wear as the material get welded to both the pin and disc material. The softer material will experience higher temperature effect leading to deformation rather than wear. This effect is observed in all the composite with reduction in wear rate.

With the increase in load the wear rate increases as more pressure on the contacting material and increase in pressure influences the wear depth, also the hard ceramics pulled out during initial stages of wear are responsible for the increase in wear rate at higher load. This can be observed from the figure 7,8 and 9 .
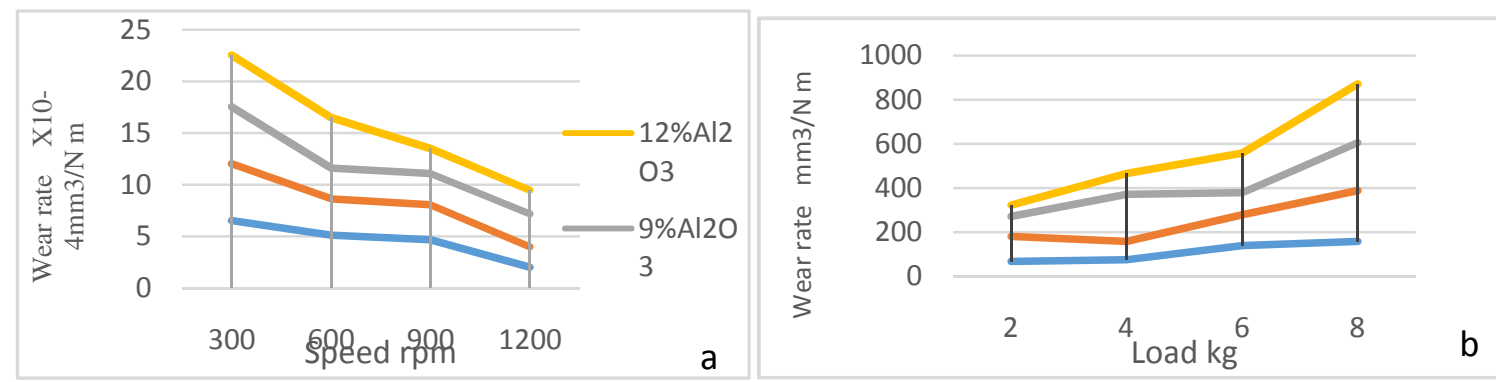

Figure 8 Wear rate vs Weight fraction for Al7075+ SiC composite at varying a) Speed 2) Load
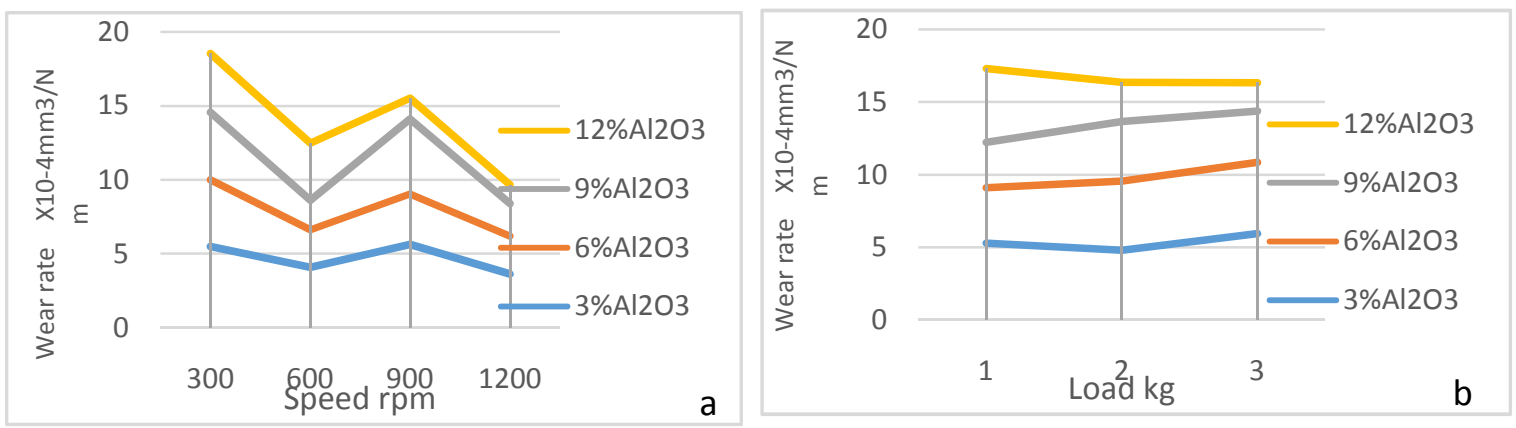

Figure 9 Wear rate vs Weight fraction for $\mathrm{Al} 7075+\mathrm{Al}_{2} \mathrm{O}_{3}+\mathrm{SiC}$ compositeat varying a) Speed 2) Load

The wear track clearly explains the mode of wear and also transition of wear state from adhesive to abrasive wear at higher load. As the speed increases the delamination wear is in progress which reduces the wear rate. At the higher load the removal of the ceramic particle influences the wear rate with more abrasive particle in the wear zone which produces large craters at higher load. With the increase in weight fraction of the reinforcements, at the higher weight fraction $(9 \%$ and $12 \%$ ) more craters can be seen.The wear track clearly indicates higher magnitude of craters lines closely packed at higher weight fraction of reinforcements as seen from the fig $10 \mathrm{~d}, 12 \mathrm{~d}$ and $14 \mathrm{~d}$. 

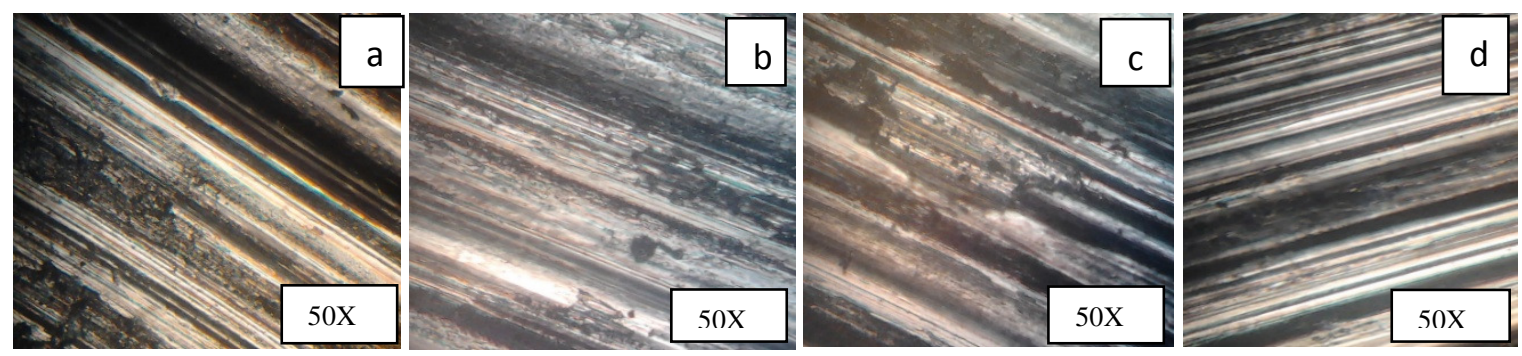

Figure 10 Optical micrograph showing different wear mechanism on the tested specimens. a) Al 7075 with $3 \% \mathrm{Al}_{2} \mathrm{O}_{3}$, b) $\mathrm{Al} 7075$ with $6 \% \mathrm{Al}_{2} \mathrm{O}_{3}$, c) $\mathrm{Al} 7075$ with $9 \% \mathrm{Al}_{2} \mathrm{O}_{3}$, d) $\mathrm{Al} 7075$ with $12 \% \mathrm{Al}_{2} \mathrm{O}_{3}$
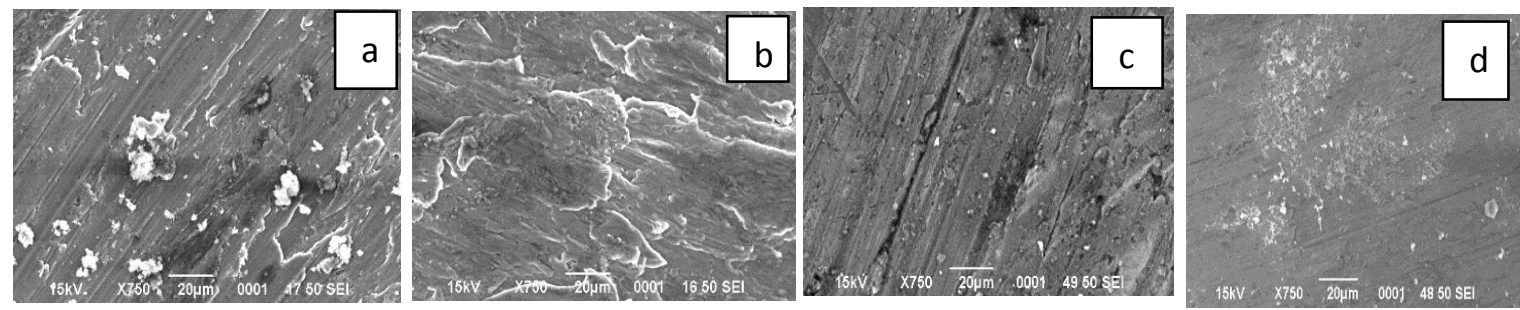

Figure 11 SEM indicating the magnitude of wear mechanisms on the specimens at weight fraction . a) $\mathrm{Al}$ 7075 with $3 \% \mathrm{Al}_{2} \mathrm{O}_{3}$, b) $\mathrm{Al} 7075$ with $6 \% \mathrm{Al}_{2} \mathrm{O}_{3}$, c) $\mathrm{Al} 7075$ with $9 \% \mathrm{Al}_{2} \mathrm{O}_{3}$, d) $\mathrm{Al} 7075$ with $12 \% \mathrm{Al}_{2} \mathrm{O}_{3}$

In order to investigate the wear mechanism during running in the worn surfaces of the specimens were studied under the microscope at 50X corresponding to the applied load of $3 \mathrm{Kg}$. The micrograph images of worn surfaces of specimens with different weight fractions are shown in fig 10,12 and 14.

The fig 12 indicates the microstructures of the different specimens tested with varying weight fractions with a load of $3 \mathrm{~kg}$ and a speed of $500 \mathrm{rpm}$. It can be observed from Fig12 that composite with weight fraction $5 \%$ to $20 \%$, which are within the transient wear regime, also show the presence of heavy wear debris particles on their worn surfaces. For composite with $20 \%$ and $15 \%$ reinforcement, which are operating in the steady-state wear regime, very little wear debris particles can be seen on the worn surfaces due to more reinforcement interaction with the disc, indicating a lower wear rate.

It should also be noted that no significant abrasive wear was observed on the worn specimens. The wear debris indicate the Adhesive wear mechanism as the predominant, as the weight fraction increases the delamination wear reduces and only specific regions where reinforcement interaction with the Disc is absence that region shows the delamination, which indicates reduction in the wear rate. The delamination wear can be observed at lower weight fraction and increases with the increase in weight fraction of the reinforcement. The composite with $3 \%$ weight fraction shows very less delamination which indicates the reduction in the wear rate. 

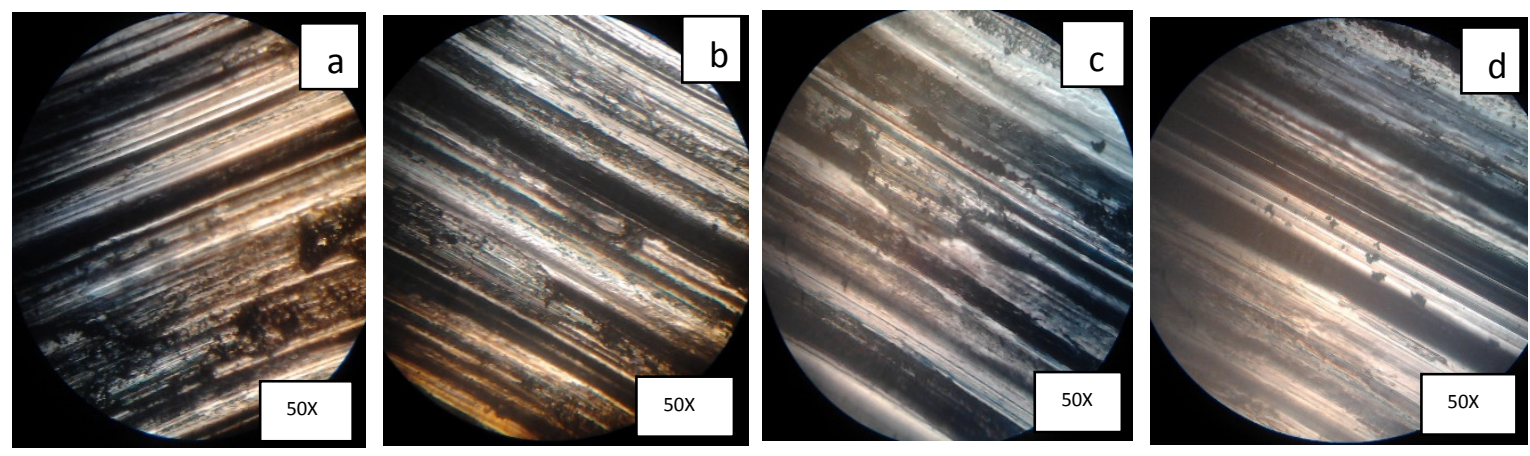

Figure 12 optical micrograph of the composite indicating the wear mechanisms on the wear test specimens a) Al 7075 with $3 \% \mathrm{SiC}$, b) Al 7075 with6\% SiC, c) Al 7075 with $9 \% \mathrm{SiC}$, d) Al 7075 with $12 \% \mathrm{SiC}$
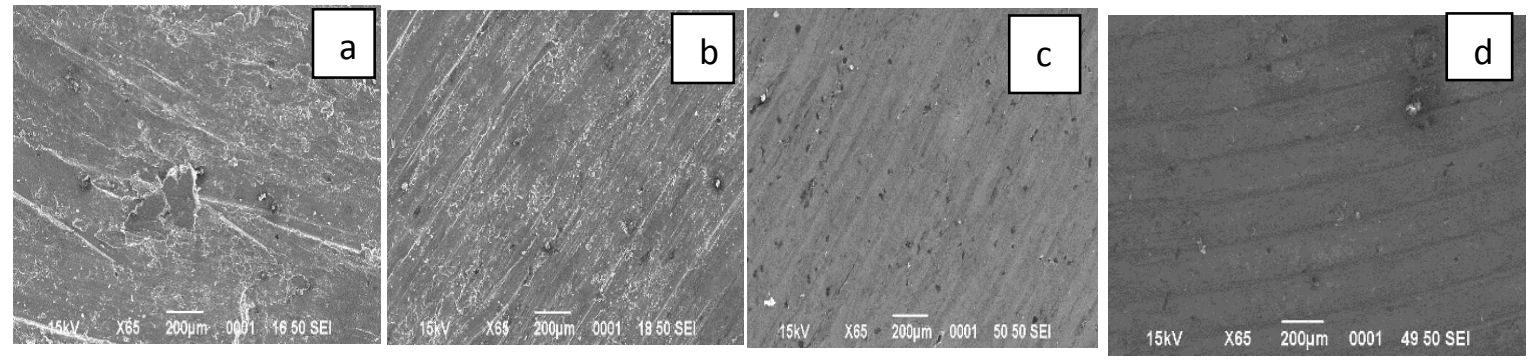

Figure 13 SEM indicating the magnitude of wear mechanisms on the wear test specimens a) Al 7075 with $3 \% \mathrm{SiC}$, b) Al 7075 with6\% SiC, c) Al 7075 with $9 \% \mathrm{SiC}$, d) Al 7075 with $12 \% \mathrm{SiC}$
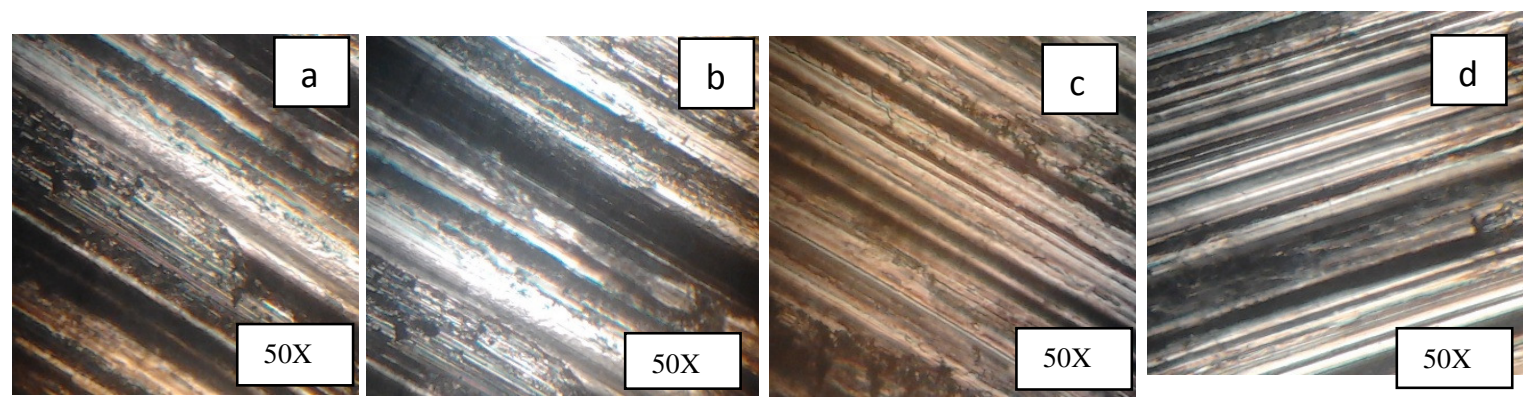

Figure 14 optical micrograph indicating the magnitude of delamination wear on the tested specimens. a) $\mathrm{Al}$ 7075 with $3 \% \mathrm{Al}_{2} \mathrm{O}_{3}+3 \% \mathrm{SiC}$, b) $\mathrm{Al} 7075$ with $6 \% \mathrm{Al}_{2} \mathrm{O}_{3}+3 \% \mathrm{SiC}$, c) Al 7075 with $9 \% \mathrm{Al}_{2} \mathrm{O}_{3}+3 \% \mathrm{SiC}$, d) Al 7075 with $12 \% \mathrm{Al}_{2} \mathrm{O}_{3}+3 \% \mathrm{SiC}$ 

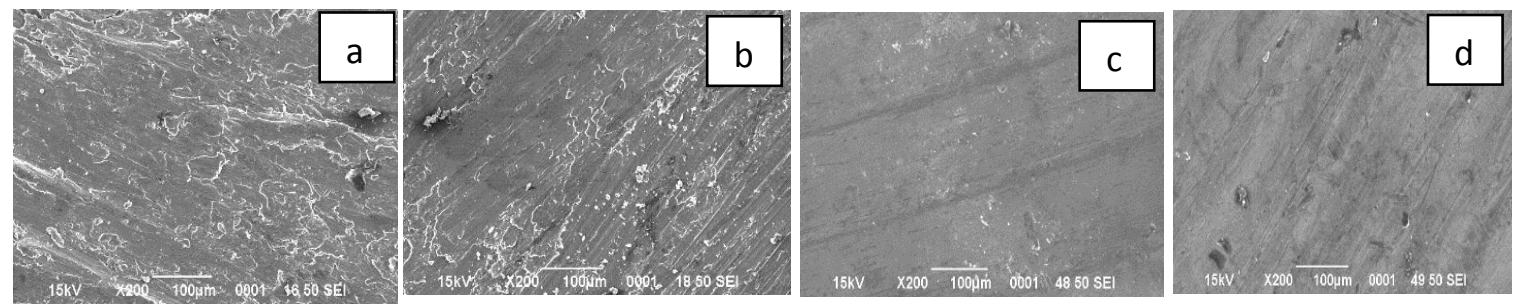

Figure 15 SEM indicating the magnitude of wear mechanisms on the wear test specimens. a) Al 7075 with $3 \% \mathrm{Al}_{2} \mathrm{O}_{3}+3 \% \mathrm{SiC}$, b) $\mathrm{Al} 7075$ with6\% $\mathrm{Al}_{2} \mathrm{O}_{3}+3 \% \mathrm{SiC}$, c) $\mathrm{Al} 7075$ with $9 \% \mathrm{Al}_{2} \mathrm{O}_{3}+3 \% \mathrm{SiC}$, d) $\mathrm{Al} 7075$ with $12 \% \mathrm{Al}_{2} \mathrm{O}_{3}+3 \% \mathrm{SiC}$

\section{CONCLUSION}

The Al7075 reinforced with Alumina, Silicon carbide and their mixture in the Particulate form with varying fractions were successfully developed by method of stir casting process using Metal mold. The particulate composite are suitable for mass production by low cost stir casting process. The uniform distribution can be achieved by stirring the matrix and reinforcement at the optimum melting temperature of $700^{\circ} \mathrm{C}$. The availability and low cost of the $\mathrm{Al}_{2} \mathrm{O}_{3}, \mathrm{SiC} \& \mathrm{Al}_{2} \mathrm{O}_{3}+\mathrm{SiC}$ reinforcement proves itself as good candidate for low cost, light weight and wear resistant automotive parts. Isotropic property is obtained with optimum stirring speed.

The density of composite was shown in fig 4 indicated the variation with weight fraction. It increases with increase in weight fraction. The porosity was is maximum for highest weight fraction of reinforcement which is due to segregation and entrapment of gases. The density of the composite is still less than the conventional alloy like steel and cast iron which can be used for light weight and fuel efficient purpose. The variation of density values from theoretical and experimental method is due to porosity it was about $20 \%$, which can be reduced by secondary process like rolling, extrusion and forging.

The optical microstructure shown in fig 3,4,5, indicates the presence of $\mathrm{Al}_{2} \mathrm{O}_{3}$, SiCand $\mathrm{AL}_{2} \mathrm{O}_{3}+$ $\mathrm{SiC}$ particles in the matrix of Aluminum. The distribution of these particle depends on the temperature of the melt and stirring speed. More agglomeration can be noticed in case of higher weight fraction of reinforcement.

The fig 6 shows hardness with increase in weight fraction, increases the hardness of the composite. The uniform variation of the hardness can be obtained with micro hardness test than the bulk hardness. The reinforcement particle influences the hardness but reduces the ductility of the alloy.

The particle reinforce composite is primarily developed for tribological application .The hard particle $\mathrm{SiC}, \mathrm{Al}_{2} \mathrm{O}_{3}$, etc. Are added for wear and strength. The behavior of these hard and soft particle exhibit different wear and friction variation in the same matrix under varying speed, load and time. The wear rate reduces with the increase in speed and lowest at the speed of $300 \mathrm{rpm}$ and 
$900 \mathrm{rpm}$. As the increase in sliding distance the wear rate reduces .wear rate increases with the increase in load. The reduction in the wear rate is due to hard particles are in contact with the disc material that are not worn out with the increase in load or sliding distance.

The coefficient of friction reduces with the increase in sliding distance, this variation is only little as the but the noise and vibrations are observed at higher speed and loads due to hard particle rubbing against the hard disc material which produces the noise due to excessive vibration and distortion of the pin. As the reinforcement is hard ceramic it will influence the reduction of the noise which can be possible with the soft ceramic like $\mathrm{SiC}$ or graphite.

1. Stir casting route for the development of particulate composite is suitable and cost effective method. Uniform distribution of the reinforcement is obtained by stirring the melt at $700^{\circ} \mathrm{C}$.

2. Enhanced strength, wear resistance and low cost composite can be developed with Alumina $\left(\mathrm{Al}_{2} \mathrm{O}_{3}\right)$ Silicon Carbide $(\mathrm{SiC})$ ceramics material. These materials are fuel efficient and light weight suitable for automobile and aircraft applications.

3. Hardness of the composite found to be increases with the increase in reinforcement weight fraction up to $20 \%$. Further increase in Ceramic particles increases the hardness at the same time the material becomes brittle due to low bond strength. Porosity level increases with weight fraction at higher rate which can be reduced by secondary process like by extrusion and rolling.

4. The density of the composite is in between the density of matrix and reinforcement material which is $50 \%$ less than the density of steel and cast iron.

5. Wear resistance of $\mathrm{Al} 7075 / \mathrm{Al}_{2} \mathrm{O}_{3}, \mathrm{Al} 7075 / \mathrm{SiC}, \mathrm{Al} 7075 / \mathrm{Al}_{2} \mathrm{O}_{3}+\mathrm{SiC}$ particulate composite increases with the weight fraction. Coefficient of friction depends on the weight fraction which reduces with increase in weight fraction.

6. The wear rate reduces with speed, but increases with load and sliding distance.

\section{ACKNOWLEDGMENT}

The Author wishes Thank BNM Institute of Technology, Bangalore for providing Lab facility and Support to Carry out the Research Work.

\section{REFERENCES}

[1] R.L Deuis, C Subramanian , J M Yellup." Dry sliding wear of aluminum composites - A review “Elsevier ,Composite society and Technology,57(1997),415-435.

[2] Kojikato "Wear in relation to friction - A review", Elsevier,Wear,241(2000),151- 157.

[3] S Naher,DBrabazon,Looney “ Simulation of Stir casting process”,Elsevier,Journal of material Processing technology,143-144(2003),567-571.

[4] K Gawdzinska, J Hajkowaski,BGlowcki ,'Impact of cooling rate on structure and tribological properties of Metal matrix Composites ",Proceedings of 18th international offshore and polar engineering conference',Canada, July 6-11-2008.

[5] S A Sajjadi,H R Ezatpour, H Beygi," Microstructure and mechanical properties of AL - Al2O3micro and nano composites fabricated by stir composites, Elsevier Material Science and Engineering A,528(2011),8765-8771. 
[6] M Kok."Production and Mechanical properties of Al2O3 particle -reinforced 2024 aluminum alloy composites", Elsevier, journal of material processing technology, 16192005, 381-387.

[7] L.J. Yang,"Wear coefficient equation foe aluminum -based matrix composites against steel disc",Elsevier, Wear,255(2003),579-592.

[8] Aluminum and Aluminum alloy, ASM International, Edited by J R Davis, Davis\& Associates, 1993.

[9] Florin Stefeneseu,GigelNeagu,AlexandriaMihai,"Practical aspect concerning the solidification of cast metallic composites",U P D science Bulletein,series B ,vol 69,No -4,2007

[10] Shao.YunFu,Xi-QiaoFeng ,Bernd Lauke,Yia-wing Mai,”Effect of Particle size ,Particle/Matrix Interface adhesion and particle loading on Mechanical properties of particulate polymer composites.',Composites,part-B-39,2008,933-961.

[11] A Al Qutqb,IAllam .A Al Ahmed and A S Elaiche,"Elevated temperature wear of submicron Al2O3 reinforced with 6061 Aluminum composites, Advanced material search , vol 83-86,2010,p12881296.

[12] El-kaddah N E and Chang K E, "The Dispersion o fSiC-Al Slurries m Rotating Flows, Materials Science \& Engineering A Structural Materials Properties, Microstructure and Processing”, A144, Oct 1 1991, p 221-227

[13] C K Fang "Effect of aging time on wear resistance of alumina particulate reinforced MMCs ", Bulletin, CIM ICM, china.2003.

[14] NamaiT ,Osawa Y and Kikuchi M , IMONO, “Journal of Japan Foundryman's Society”, 56, 1984, pp 604-609

[15] J Hashim, Llooney, M S J Hashmi "Particle distribution in cast metal composites -Part I " Journal Of material processing technology ,123,(2002),251-257.

[16] S SRizam et al , "Effect of particle coating on Matrix -reinforcement Bonding",ICoSM ,2007,Malaysia.

[17] ZhiQia YU, et al," Microstructure and Tensile Properties of Yttria coated -Alumina particulates reinforced Aluminum matrix composites.

[18] H. R. Ezatpour, M. Torabi-Parizi, S. A. Sajjadi , "Microstructure and mechanical properties of extruded Al/A12O3 composites fabricated by stir-casting process", Trans. Nonferrous Met. Soc. China 23(2013) 1262-1268.

[19] A. Włodarczyk-Fligier, L.A. Dobrzański*, M. Kremzer, M. Adamiak, “ Manufacturing of aluminium matrix composite materials reinforced by $\mathrm{Al} 2 \mathrm{O} 3$ particles", Journal of Achievements in Materials and Manufacturing Engineering, Volume 27 Issue 1 March 2008.

[20] L.J. Yang, "The effect of nominal specimen contact area on the wear coefficient of A6061 aluminium matrix composite reinforced with alumina particles", Wear 263 (2007) 939-948.

[21] Krzysztof Naplocha,Jacek W. Kaczmar , "Wear Behavior of Fiber-Reinforced Aluminum Alloy Composites", Advanced Materials \& Processes • March 2012.

\section{AUTHORS}

Raghavendra.N working at BNMIT, Bangalore as Associate Professor. Having 17 years of Experience in teaching. Currently carrying out research on Development and tribology studies on MMC for automobile applications.

Dr V.S. Ramamurthy working at Yellamma Dasappa I T, Bangalore, is a Professor \&HOD having 30 years of Academic experience in various capacity. Working on development and Analysis of Chill casting of PMMC. Presently guiding 5 PhD scholars.
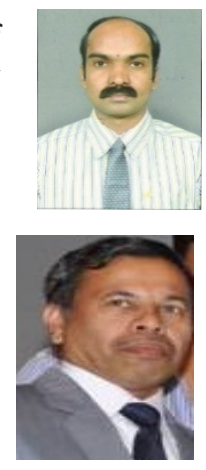